JURNAL Midwifery Update (MU)

http://jurnalmu.poltekkes-mataram.ac.id/index.php/jurnalmu

e-ISSN: 2684-8511 (Online)

\title{
DIGITALISASI DOKUMEN INSTRUKSI KERJA ALAT DENGAN MENGGUNAKAN QUICK RESPONSE (QR) CODE PADA ALAT LABORATORIUM JURUSAN ANALIS KESEHATAN DAN JURUSAN KEBIDANAN POLTEKKES KEMENKES MATARAM
}

\author{
R.A Wulandarii ${ }^{1 凶}$, Affan Ardiyanto ${ }^{2}$ \\ ${ }^{1}$ Jurusan Kebidanan, Poltekkes Kemenkes Mataram, Indonesia \\ ${ }^{2}$ Jurusan Analis Kesehatan, Poltekkes Kemenkes Mataram, Indonesia
}

\begin{abstract}
Abstrak
Laboratorium adalah salah satu sarana terpenting pada pelaksanaan pendidikan vokasi. Berdasarkan hasil observasi pada laboratorium jurusan analis kesehatan dan jurusan kebidanan Poltekkes Kemenkes Mataram, dokumen instruksi kerja alat pada kertas HVS dan dipasang dengan cara di tempel pada dinding terdekat atau di gantungkan pada bagian alat untuk mempermudah akses dokumen tersebut. Hal tersebut membuat dokumen instruksi kerja alat cepat rusak dan hilang. Dengan perkembangan teknologi yang semakin maju dan pesat, permasalahan tersebut dapat diatasi dengan digitalisasi dokumen instruksi kerja dengan tujuan untuk meningkatkan keamanan penyimpanan, memudahan akses, dan membuat ukuran dokumen instruksi kerja lebih efisien. Salah satu pilihan praktis untuk digitalisasi adalah dengan menggunakan Sistem Quick Response Code ( $Q R$ Code). Sistem tersebut dapat meningkatkan keamanan penyimpanan dan kecepatan akses informasi didalamnya. Selain itu $Q R$ Code memiliki tampilan yang kecil dan masih dapat terpindai meskipun mengalami kerusakan fisik hingga $30 \%$. Penelitian ini dilakukan di Laboratorium Jurusan Analis Kesehatan dan Jurusan Kebidanan selama 8 bulan mulai bulan Juni 2020 s.d Februari 2021. Penelitian dilakukan dalam 5 tahapan mulai dari pengumpulan dokumen instruksi kerja , menggunggah dokumen instruksi kerja, implementasi $Q R$ code, uji coba $Q R$ code dengan $Q R$ scanner dan terakhir menempelkan $Q R$ code pada alat laboratorium sehingga dapat digunakan oleh pengguna. Dalam pengujian fungsionalitas $Q R$ code, digunakan metode pengujian blackbox. Hasil yang diperoleh dari identifikasi dokumen instruksi kerja alat yakni sebanyak 50 alat di laboratorium jurusan analis kesehatan dan 20 alat di laboratorium jurusan kebidanan telah berhasil dibuat $Q R$ Code. Dengan dilakukannya penelitian ini, diharapkan sistem pengelolaan laboratorium dapat ditingkatkan
\end{abstract}

Kata Kunci : Digitalisasi, Instruksi Kerja Alat, Quick Response Code

\section{DIGITALIZATION OF TOOL MANUAL INSTRUCTIONS USING QUICK RESPONSE (QR) CODE IN LABORATORY EQUIPMENT DEPARTMENT OF HEALTH ANALYSIS AND MIDWIFE DEPARTMENT OF POLTEKKES KEMENKES MATARAM}

RA Wulandarii ${ }^{1 \bowtie}$, Affan Ardiyanto ${ }^{2}$

${ }^{1}$ Department of Midwifery, Poltekkes Kemenkes Mataram, Indonesia

${ }^{2}$ Department of Health Analyst, Ministry of Health Poltekkes Mataram, Indonesia

\begin{abstract}
The laboratory is one of the most important facilities in the implementation of vocational education. Based on the results of observations at the laboratory of the Department of Health Analysts and the Department of Midwifery, Poltekkes, the Ministry of Health, Mataram, the tool manual instruction document was on HVS paper and installed by sticking it on the nearest wall or hanging it on the tool to facilitate access to the document. This makes the tool work instruction document quickly damaged and lost. With the development of increasingly advanced and rapid
\end{abstract}


technology, these problems can be overcome by digitizing work instruction documents with the aim of increasing storage security, facilitating access, and making the size of work instruction documents more efficient. One practical option for digitizing is to use a Quick Response Code (QR Code) system. The system can improve storage security and speed of access to information in it. In addition, the QR Code has a small display and can still be scanned despite up to $30 \%$ physical damage. This research was conducted at the Laboratory of the Health Analyst Department and the Midwifery Department for 8 months starting from June 2020 to February 2021. The research was carried out in 5 stages starting from collecting manual instruction documents, uploading manual instruction documents, implementing QR codes, testing QR codes with QR scanners and finally paste the QR code on the laboratory equipment so that it can be used by users. In testing the QR code functionality, the blackbox testing method is used. The results obtained from the identification of tool manual instruction documents, namely as many as 50 tools in the laboratory of the health analysis department and 20 tools in the laboratory of the obstetrics

department, have been successfully made QR Code. With this research, it is hoped that the laboratory management system can be improved better

\section{Keywords: Digitization, Tool Manual Instructions, Quick Response Code}




\section{Pendahuluan}

Dokumen instruksi kerja alat laboratorium merupakan salah satu perangkat yang harus diperhatikan dalam mengelola suatu laboratorium. Instruksi kerja alat yang berisi standar penggunaan alat yang benar. Dokumen ini dibuat agar masa pakai alat menjadi lebih lama dan awet. Lazimnya, instruksi kerja memuat informasi tentang spesifikasi alat, fungsi alat, cara menggunakan alat sehingga lebih jelas serta cara perawatannya ${ }^{2}$

Berdasarkan hasil observasi pada laboratorium jurusan analis kesehatan dan jurusan kebidanan Poltekkes Kemenkes Mataram, dokumen instruksi kerja alat pada kertas HVS dan dipasang dengan cara di tempel pada dinding terdekat atau di gantungkan pada bagian alat untuk mempermudah akses dokumen tersebut. Hal tersebut membuat dokumen instruksi kerja alat cepat rusak dan hilang. Terutama untuk peralatan laboratorium yang berukuran kecil, maka instruksi kerja alat tersebut akan sangat mengganggu dan kurang efektif,yang secara tidak langsung mengakibatkan tidak diperolehnya informasi oleh pengguna tentang tata cara penggunaan alat laboratorium yang baik dan benar.

Dengan perkembangan teknologi yang semakin maju dan pesat, permasalahan tersebut dapat diatasi dengan digitalisasi dokumen instruksi kerja dengan tujuan untuk meningkatkan keamanan penyimpanan, memudahan akses, dan membuat ukuran dokumen instruksi kerja lebih efisien.

Salah satu pilihan praktis untuk digitalisasi adalah dengan menggunakan Sistem Quick Response Code (QR Code). Sistem tersebut dapat meningkatkan keamanan penyimpanan dan kecepatan akses informasi didalamnya. Selain itu QR Code memiliki tampilan yang kecil dan masih dapat terpindai meskipun mengalami kerusakan fisik hingga $30 \%$. Berdasarkan latar belakang tersebut, penulis ingin melakukan penelitian untuk digitalisasi dokumen instruksi kerja alat laboratorium dengan penerapan QR Code yang akan dilakukan pada alat laboratorium jurusan analis kesehatan dan jurusan kebidanan Poltekkes Kemenkes Mataram sebagai bentuk sistem pendukung dalam pengelolaan alat laboratorium.

\section{Metode Penelitian}

Penelitian ini dilakukan selama 8 bulan, mulai bulan Juni 2020 hingga Februari 2021 di laboratorium Jurusan Analis Kesehatan dan Jurusan Kebidanan Poltekkes Kemenkes Mataram. Tahapan Alur Penelitian sebagai berikut :

1. Pada tahap pertama, penelitian dimulai dengan membuat dan/atau mengumpulkan serta mengidentifikasi Instruksi Kerja Alat pada Laboratorium Jurusan Analis Kesehatan dan Jurusan Kebidanan

2. Tahap Kedua dilanjutkan dengan mengunggah dokumen instruksi kerja alat, buku manual alat (jika ada) dan foto alat di unggah pada link google drive.

3. Tahap Ketiga dilanjukan dengan membuat $Q R$ Code dan mengaplikasikan $Q R$ code tersebut pada dokumen instruksi kerja alat untuk semua alat laboratorium jurusan analis kesehatan dan jurusan kebidanan 
4. Tahap Keempat adalah uji coba metode blackbox $Q R$ Code dengan menggunakan $Q R$ scanner, apakah QR yang dibuat sudah berhasil menampilkan Instruksi kerja alat dimaksud.

5. Tahap Kelima, mencetak $Q R$ code yang sudah berhasil dibuat dengan kertas anti luntur lalu menempelkan pada alat-alat dimaksud agar dapat digunakan langsung oleh pengguna alat.

Adapun alat dan bahan yang digunakan dalam penelitian ini adalah seperangkat komputer, aplikasi pembuat $Q R$ Code, aplikasi QR Code Scanner, Google Drive, aplikasi Microsoft Word, printer, mesin laminating, gunting, dan penggaris. Sedangkan bahan yang digunakan dalam penelitian ini adalah kertas HVS, kertas anti luntur, plastik laminating, dan double tape.

\section{Hasil Penelitian dan Pembahasan}

1. Identifikasi Instruksi Kerja Alat

Berdasarkan hasil identifikasi, dokumen Intruksi Alat di Laboratorium Jurusan Analis Kesehatan baru mencapai 83,3\% yaitu 50 dokumen dari 60 alat yang memerlukan instruksi kerja dan manual prosedur alat. Hal ini dikarenakan dokumen instruksi kerja alat belum dibuat/disusun oleh penanggung jawab laboratorium.

Sedangkan dokumen instruksi kerja alat pada laboratorium jurusan kebidanan yang disimpan di ruang sentral laboratorium, baru mencapai $80 \%$, yaitu 20 dokumen dari total 25 alat yang memerlukan instruksi kerja alat / manual prosedur berdasarkan kriteria. Hal ini dikarenakan penanggung jawab laboratorium belum menyusun dokumen instruksi kerja alat laboratorium tersebut dan tidak ditemukannya arsip (hard copy) manual prosedur alat baik d laboratorium maupun pencairan dengan mesin pencari "google".

2. Digitalisasi Dokumen Instruksi Kerja Alat

Tabel 1. Hasil Digitalisasi Dokumen Instruksi Kerja Alat dengan $Q R$ Code pada Alat Laboratorium Jurusan Kebidanan

\begin{tabular}{|c|c|c|c|}
\hline No & Nama Alat & Gambar QR Code & Gambar Alat \\
\hline 1 & Airway Larry Torso & 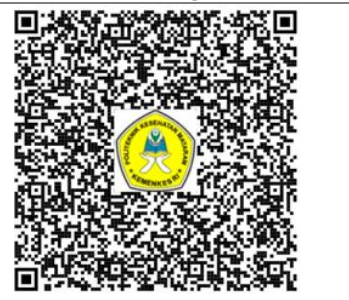 & \\
\hline 2 & $\begin{array}{l}\text { Baby Buddy Infant CPR } \\
\text { Manikin }\end{array}$ & 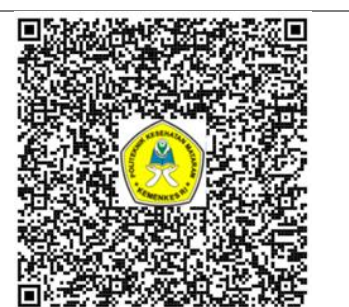 & \\
\hline
\end{tabular}




\begin{tabular}{|c|c|c|c|}
\hline 3 & $\begin{array}{l}\text { Basic Buddy } \text { CPR } \\
\text { Manikin }\end{array}$ & 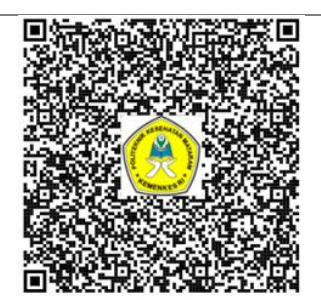 & $x=1$ \\
\hline 4 & Cardiotocography & 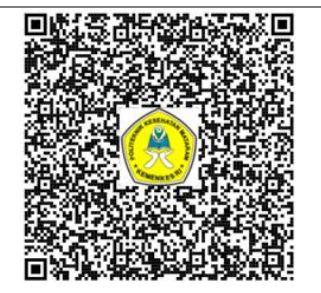 & 000 \\
\hline 5 & Fetal Doppler & 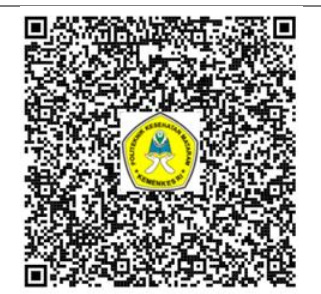 & \\
\hline 6 & Infant Incubator & 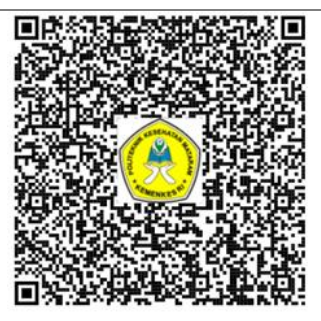 & \\
\hline 7 & Infant Warmer & 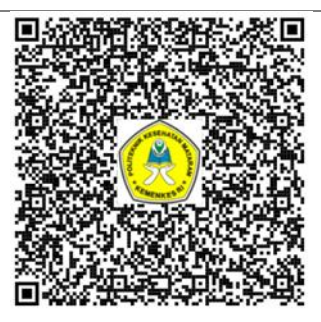 & 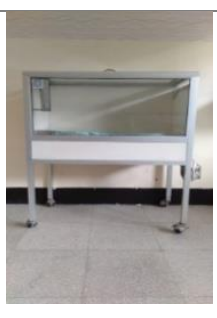 \\
\hline 8 & Intramuscular simulator & 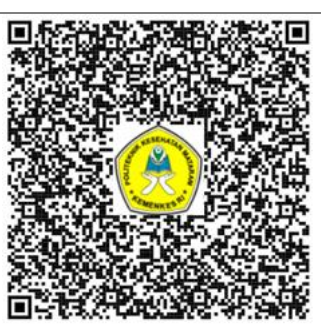 & \\
\hline
\end{tabular}


9 Intravenous arm
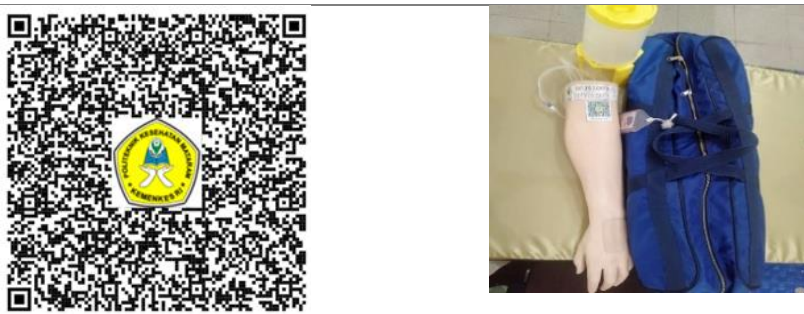

10 Keele Staff episiotomy
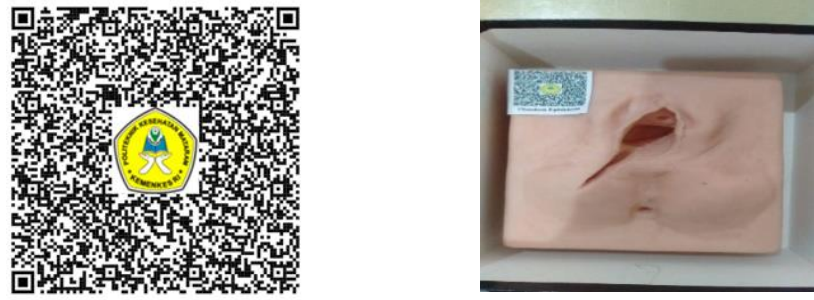

11 Buttock mate Type II
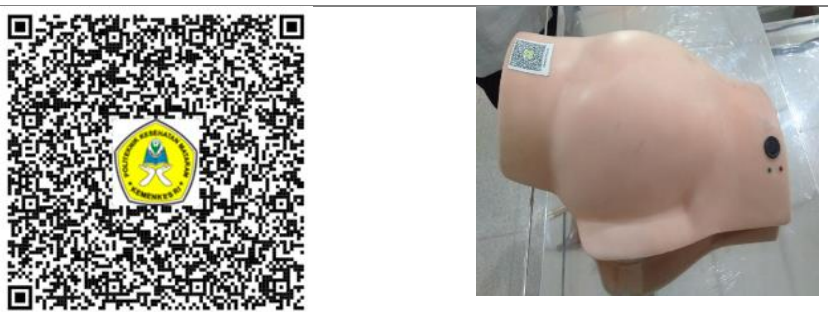

12 Newborn baby vital signs simulator
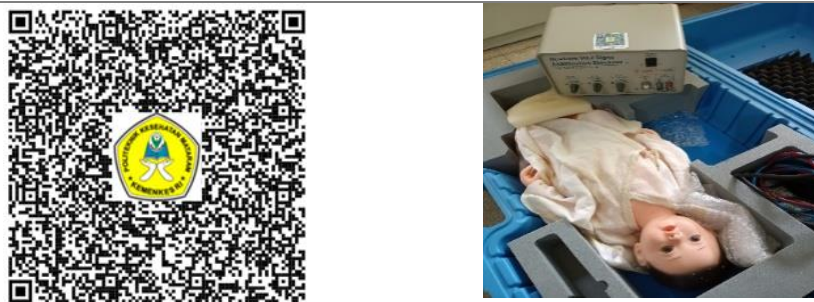

13 Maternal Birthing
Simulator
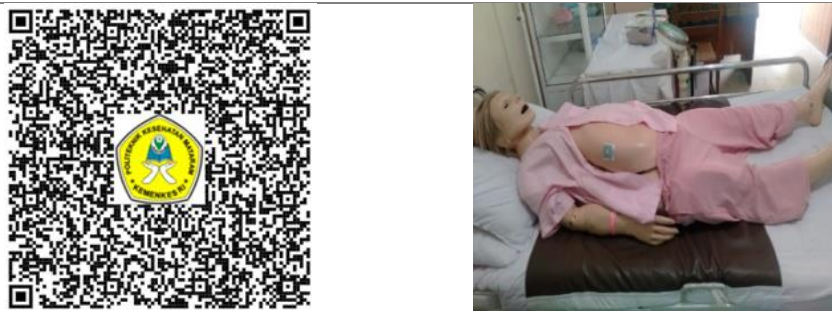

14 Digital tensimeter
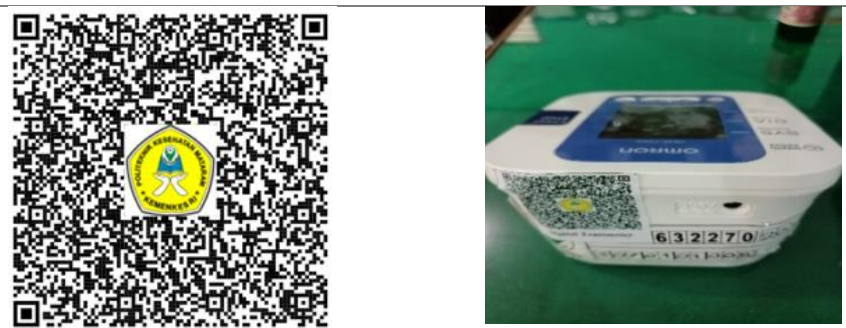
15 Peripheral venous arm
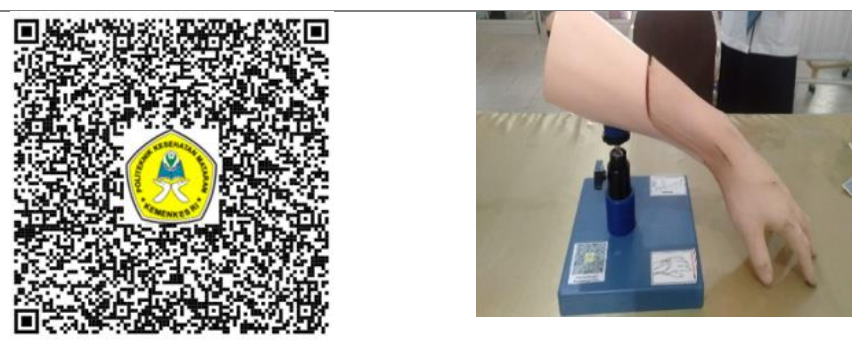

16 Birthing simulator
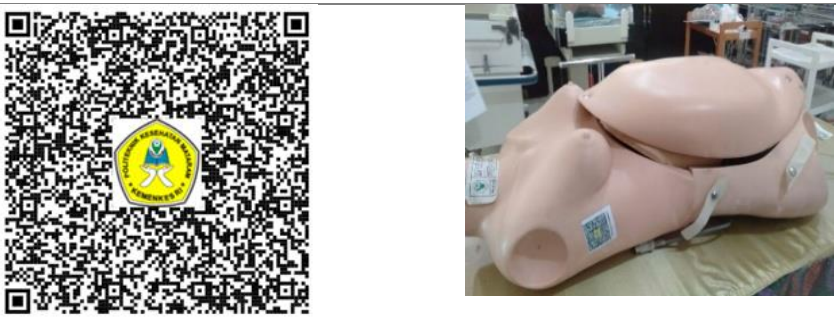

17 EVA Pelvic simulator
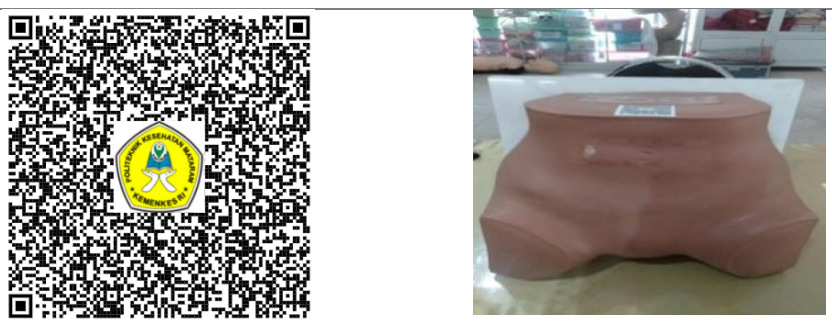

18 Timbangan Digital
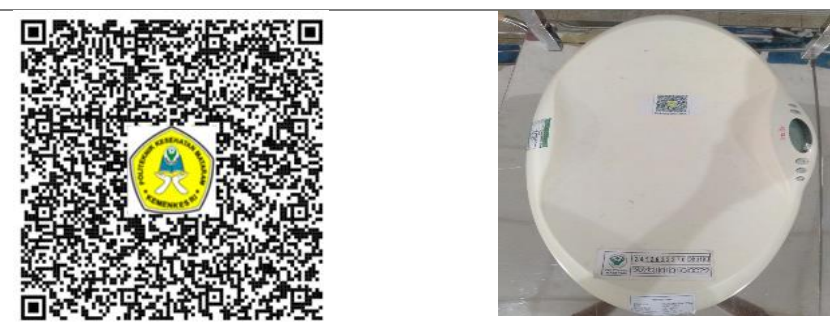

19 Ultrasonografi
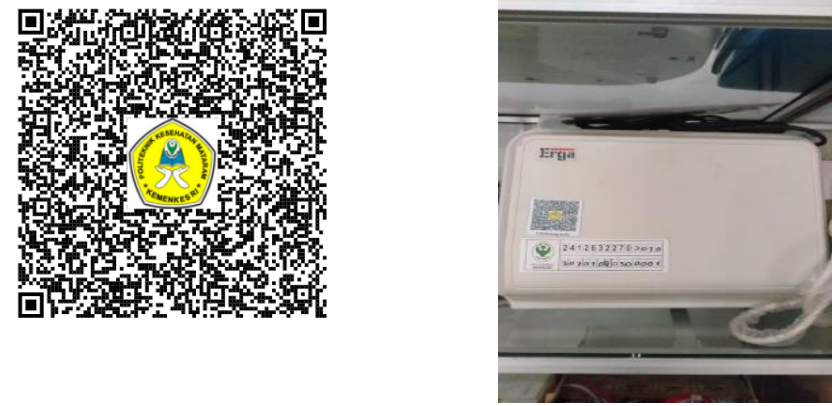

Tahap akhir penelitian ini adalah uji coba pengoperasian QR code. Dalam pengujian fungsionalitas QR code, digunakan metode pengujian blackbox. Pengujian Blackbox adalah pengujian yang sistemnya tanpa memperhatikan struktur logika internal perangkat lunak. Metode ini biasanya digunakan pada sistem perangkat lunak untuk mengetahui apakah sistem tersebut berfungsi dengan benar ${ }^{3}$. 
Pada metode ini QR code yang telah terpasang di setiap alat diuji fungsionalitasnya menggunakan aplikasi QR-Code Scanner dalam handphone dan kemudian keluaran dari hasil pemidaian dicek apakah telah sesuai dengan yang diharapkan atau tidak. Pada proses pemindaian, smartphone berhasil merespon QR code, yaitu dengan munculnya dialog Link URL di layar Smartphone. Tampilan dialog hasil pemindaian QR code disajikan pada Gambar 1.

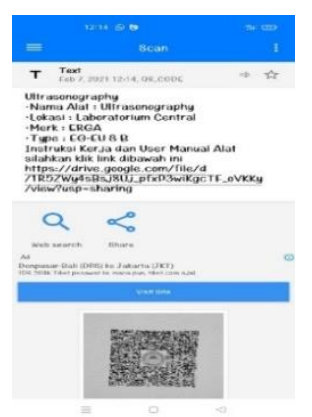

Gambar 1. Tampilan dialog hasil pemindaian QR code

Ketika Link URL dijalankan pada web browser, sistem melakukan deskripsi pada URL, kemudian dicocokkan dengan database, dan selanjutnya ditampilkan ke web browser berupa dokumen instruksi kerja alat.

Dari hasil pengujian di atas, diperoleh data bahwa QR Code berfungsi sesuai yang diharapkan, yaitu hasil pemindaian QR Code menampilkan alamat URL yang selanjutnya dienkripsikan dalam bentuk dokumen Instruksi kerja pada layar handphone sehingga seorang pengguna alat tidak perlu susah mencari file hardcopy Instruksi kerja alat yang akan dioprasikan. Pengguna alat cukup melakukan pemindaian pada QR Code yang telah terpasang di masing-masing alat, dimana dalam waktu singkat pengguna alat mendapatkan dokumen Instruksi kerja alat di handphone nya.

\section{Kesimpulan dan Saran}

QR Code pada dokumen instruksi kerja alat di laboratorium jurusan analis kesehatan dan jurusan kebidanan telah dibuat $100 \%$, dan dari hasil uji coba setiap QR Code telah berhasil menampilkan dokumen instruksi kerja alat dalam bentuk file digital pada handphone pengguna. Sehingga dapat disimpulkan bahwa QR-Code menjadi salah satu solusi untuk menyimpan dan menampilkan dokumen instruksi kerja alat laboratorium secara lebih efisien sehingga pengguna lebih mudah dalam mengakses dokumen instruksi kerja alat laboratorium tersebut.

Diharapkan pada pranata laboratorium pendidikan (PLP) di jurusan analis kesehatan dan jurusan kebidanan agar dapat melengkapi dokumen instruksi kerja alat maupun manual prosedur pabrik pada masing-masing alat hingga $100 \%$ sehingga pengguna dapat memahami cara mengoperasikan dan pemeliharaan alat laboratorium tersebut; selanjutnya Para PLP agar mengembangkan penelitian ini dengan menguji efektifitas QR code sebagai salah satu terobosan 
untuk arsip digital dokumen-dokumen instruksi kerja alat maupun dokumen penting lainnya di laboratorium.

\section{Daftar Pustaka}

1. Kementerian Pendidikan dan Kebudayaan Republik Indonesia. Peraturan Menteri Pendidikan Dan Kebudayaan Republik Indonesia Nomor 3 Tahun 2020 Tentang Standar Nasional Pendidikan Tinggi

2. Ismail. R. (2015). Sistem Managemen Laboratorium : Instruksi Kerja Alat Institut Pertanian Bogor. Diakses 04 Desember 2019 pada Word Wide Web : http://rohmatchemistry.staff.ipb.ac.id/2015/10/12/sistemmanagemen-laboratorium-instruksikerja-alat/. Jurnal Pengelolaan Laboratorium Pendidikan, 1 (2) 2019, 48-53, e-ISSN: 2654$251 \mathrm{X}$

3. Denso Wave Incorporated. (2013). Answers to your question about the QR Code. (Online) http://www.qrcode.com/en/ (Diakses tanggal 20 Februari 2020.

4. Kementerian Pendidikan dan Kebudayaan Republik Indonesia. Lampiran Peraturan Menteri Pendidikan Dan Kebudayaan, Nomor 7 Tahun 2019 Tentang Petunjuk Teknis Jabatan Fungsional Pranata Laboratorium Pendidikan Dan Angka Kreditnya

5. Ketut Sumada, Work Instruction (Instruksi Kerja) Peralatan Laboratorium,http://ketutsumada.blogspot.co.id/2012/02/instruksi-kerja-peralatanlaboratorium.html, diakses pada tanggal 15 Oktober 2020

6. Muharom, Lutfi Ali. 2014. Penerapan Model Presensi Ujian Semester berbasis quick Response Code (QR Code) di Universitas Muhammadiyah Jember. Jurusan Teknik Informatika Fakultas Teknik, Universitas Muhammadiyah Jember.

7. Musthofa N. A, Mutrofin S, Murtadho M. A. 2016. Implementasi Quick Response (QR) Code Pada Aplikasi Validasi Dokumen Menggunakan Perancangan Unified Modelling Language (UML). Jurnal Ilmiah dan Teknik Informatika Vol. 10, No. 1. 1 Mei 2016: 42-50.

8. Poltekkes Kemenkes Mataram. 2019. Profil Laboratorium Poltekkes Kemenkes Mataram.

Mataram : Poltekkes Kemenkes Mataram

9. Suyanta, 2010. Manajemen Operasional laboratorium. Universitas Negeri Yogyakarta, Yogyakarta.

10. Wangsa, Prastyo. 2018. Implementasi Quick Response (QR) Code pada dokumen Instruksi Kerja Alat Laboratorium Kimia. Universitas Gadjah Mada Yogyakarta. Available online at JPLP Website: https://ejournal2.undip.ac.id/index.php/jplp 